\title{
Emergency department characteristics and capabilities in Bogotá, Colombia
}

\author{
Yury Bustos ${ }^{1 *}$, Jenny Castro ${ }^{2}$, Leana S. Wen ${ }^{3}$, Ashley F. Sullivan ${ }^{4}$, Dinah K. Chen ${ }^{4}$ and Carlos A. Camargo Jr. ${ }^{4}$
}

\begin{abstract}
Background: Emergency departments (EDs) are a critical, yet heterogeneous, part of international emergency care. The National ED Inventories (NEDI) survey has been used in multiple countries as a standardized method to benchmark ED characteristics. We sought to describe the characteristics, resources, capabilities, and capacity of EDs in the densely populated capital city of Bogotá, Colombia.

Methods: Bogotá EDs accessible to the general public 24/7 were surveyed using the 23-item NEDI survey used in several other countries (www.emnet-nedi.org). ED staff were asked about ED characteristics with reference to calendar year 2011.

Results: Seventy EDs participated (82\% response). Most EDs (87\%) were located in hospitals, and $83 \%$ were independent hospital departments. The median annual ED visit volume was approximately 50,000 visits. Approximately $90 \%$ (95\% confidence interval (CI) 80-96\%) had a contiguous layout, with medical and surgical care provided in one area. Almost all EDs saw both adults and children (91\%), while $6 \%$ saw only adults and $3 \%$ saw only children. Availability of technological and consultant resources in EDs was variable. Nearly every ED had cardiac monitoring (99\%, $95 \%$ Cl 92-100\%), but less than half had a dedicated CT scanner (39\%, $95 \%$ Cl 28-52 \%). While most EDs were able to treat trauma $24 / 7$ ( $81 \%, 95 \%$ Cl 69-89 \%), few could manage oncological (22\%, $95 \%$ Cl 13-34 \%) or dental (3\%, $95 \%$ Cl 0-11\%) emergencies 24/7. The typical ED length-of-stay was between 1 and $6 \mathrm{~h}$ in $59 \%$ of EDs $(95 \% \mathrm{Cl}, 46-70 \%)$, while most others reported that patients remained for $>6 \mathrm{~h}(39 \%)$. Almost half of respondents (46\%, $95 \% \mathrm{Cl} 34-59 \%$ ) reported their ED was over capacity.
\end{abstract}

Conclusions: Bogotá EDs have high annual visit volumes and long length-of-stay, and half are over capacity. To meet the emergency care needs of people in Bogotá and other large cities, Colombia should consider improving urban ED capacity and training more emergency medicine specialists capable of efficiently staffing its large and crowded EDs.

Keywords: International emergency medicine; Bogotá, Colombia; Emergency department classification; Health policy; Emergency department crowding

\section{Background}

With a population of 7.5 million people, Bogotá is not only Colombia's largest city but one of the largest cities in South America [1]. The Colombian health system establishes health care as a fundamental right for all citizens. Law 100 of 1993 established the benefit of insurance plans, with an eventual goal of providing coverage to the

\footnotetext{
* Correspondence: yury.bustos@urosario.edu.co

Prior presentation: Preliminary results presented at the 2nd International Congress in Emergency Medicine, Bogotá, Colombia (November 8, 2012). 'Department of Emergency Medicine, Universidad del Rosario, Carrera $24 \mathrm{~N}^{\circ}$ 63C-69, Bogotá, Colombia

Full list of author information is available at the end of the article
}

entire population [2]. After several reforms to advance this and other goals, health insurance coverage in Colombia has reached approximately $90 \%$, and health expenditures account for approximately $7.6 \%$ of the gross domestic product. Unfortunately, the supply of physicians is insufficient to meet the demand resulting from these health system changes. At present, for every 10,000 people, there are only 1.5 physicians [3].

These major health system changes directly affect emergency care, which, by its nature, requires immediate attention and exposes deficiencies of the system [4]. The description and study of emergency departments (EDs),

\section{Springer}

(c) 2015 Bustos et al. Open Access This article is distributed under the terms of the Creative Commons Attribution 4.0 International License (http://creativecommons.org/licenses/by/4.0/), which permits unrestricted use, distribution, and reproduction in any medium, provided you give appropriate credit to the original author(s) and the source, provide a link to the Creative Commons license, and indicate if changes were made. 
as the basic unit for the emergency care system, can improve understanding of the strengths and weaknesses of Colombian emergency care, and enable comparison with other emergency care systems worldwide, as Colombia and many other countries search for solutions to common problems [5]. Data obtained in the National Emergency Department Inventory (NEDI) project has demonstrated already how heterogeneous EDs are within the same city and in different parts of a country [6,7]. Our objective was to use the NEDI instrument to describe the fundamental characteristics of Bogotá EDs, with particular attention to available resources, capabilities, and capacity of these EDs.

\section{Methods}

This was a cross-sectional descriptive study with webbased surveys administered to the physician-administrator at each Bogotá ED. Consistent with terminology used in NEDI-USA, an ED was defined as an emergency care facility that is open $24 \mathrm{~h}$ per day, 7 days per week. A list of EDs was obtained from the Centro Regulador de Urgencias y Emergencias de Bogotá and verified for completeness by two local emergency physicians (YB, JC). All eligible EDs were contacted and surveyed in 2012. The study was coordinated by the Emergency Medicine Network (EMNet) in Boston (www.emnet-nedi.org). This study was approved by the Ethics Committee of the Universidad del Rosario and determined to be exempt by the Partners Institutional Review Board.

The 23-item NEDI instrument was used. Participants were specifically asked in 2012 about ED characteristics with reference to calendar year 2011. Survey questions were drawn, in part, from a survey that has been administered in hundreds of US EDs [7]. Questions were subdivided into four categories: ED characteristics, patient experiences in the ED, capacity, and resources and capabilities. Before implementation, survey questions were reviewed by members of the EMNet Steering Committee and several on-site country coordinators of prior NEDI international surveys $[6,8-12]$. The survey was translated into Spanish by a professional interpreter service and independently checked for accuracy by two bilingual emergency physicians (Additional file 1).

Because many Bogotá ED directors reported uncertainty about their estimate of annual ED visit volume (when completing the original 23-item survey), we then distributed a 5-item follow-up survey to check reliability of this key variable. The follow-up survey included the following variables: number of hospital beds, annual ED visit volume, percent of ED visits that led to hospital admission, number of hospital admissions, and percent of hospital admissions that were admitted through the ED.

Responses were entered into LimeSurvey (www.limesurvey.org) and downloaded into an Excel spreadsheet
(Microsoft Corp., Redmond, WA). Responses received were maintained on a secure, password-protected server. Descriptive statistics, Wilcoxon rank-sum test, and Fisher's exact test were calculated using Stata 11.0 (StataCorp, College Station, TX).

\section{Results}

\section{General characteristics}

Among the 85 EDs in Bogotá at the time of survey administration, $54 \%$ were located in private hospitals and $42 \%$ were in teaching hospitals. Additional file 2 shows a map of the 85 EDs that were surveyed. Out of 85 EDs in Bogotá, 70 participated in the primary survey (82\% response rate). Respondent and non-respondent EDs did not differ with respect to ownership, metropolitan status, or academic status (data not shown). As shown in Table 1, $87 \%$ were located in hospitals, and $83 \%$ were independent hospital departments (i.e., not under the jurisdiction of medicine or surgery departments). Approximately $90 \%$ had a contiguous layout with medical and surgical care provided in one area, with most (67\%) using triage to service (i.e., triage of patients to a specific emergency service, for example, medical vs surgical team). Almost all EDs saw both adults and children (91 $\%$ ), while $6 \%$ saw only adults and $3 \%$ saw only children. The main survey $(n=70)$ yielded an estimate of 61,637 annual ED visits per year (median). Several respondents reported difficulty obtaining their ED visit volume data, and, for this reason, we performed a second survey of the participating sites to provide directors with more time and to assess the reliability of the original estimate. Among the 37 repeat respondents (53\% of the original 70 EDs), the median annual ED visit volume was 44,457 visits, with no significant difference in the median number of ED visits between surveys $(P=0.47)$. Comparing the two surveys, there was no significant difference in the number of hospitals beds, but there was a significant difference in the reported percentage of ED visits leading to admission and percentage of total hospital admissions through the ED (Table 2). Based on a population of $7,467,804$ million (1), the estimated total number of ED visits in Bogotá yielded a population ED visit rate of between 627 (follow-up survey) and 772 (main survey) ED visits per 1000 people. Figure 1 provides a "snapshot" of the overall ED characteristics in Bogotá, using the approach used in several prior NEDI international surveys $[6,8-12]$.

\section{Patient experiences in the ED}

Most respondents (63\%) answered that $<20 \%$ of their patient population arrived by ambulance. In $59 \%$ of EDs, the average length-of-stay was between 1-6 h; in $38 \%$, the average length-of-stay was $>6 \mathrm{~h}$. Among EDs with an annual visit volume of 100,000 visits or more, 57 
Table 1 Characteristics of EDs in Bogotá, Colombia, based on the 70 sampled EDs

\begin{tabular}{|c|c|c|}
\hline & Proportion or median & $95 \%$ confidence interval or interquartile range \\
\hline \multicolumn{3}{|l|}{ General characteristics } \\
\hline Hospital based & $87 \%$ & $77-94 \%$ \\
\hline Independent department & $83 \%$ & $72-91 \%$ \\
\hline Contiguous & $90 \%$ & $81-96 \%$ \\
\hline Triage to service ${ }^{a}$ & $67 \%$ & $54-78 \%$ \\
\hline \multicolumn{3}{|l|}{ Annual ED visits (median) } \\
\hline From main survey $(n=70)$ & 61,637 & $29,900-114,159$ \\
\hline From follow-up survey $(n=37)$ & 44,457 & $19,920-129,215$ \\
\hline ED beds (median) & 19 & $11-37$ \\
\hline \multicolumn{3}{|l|}{ Patient experiences in ED } \\
\hline \multicolumn{3}{|l|}{ Percent of ED patients arriving by ambulance } \\
\hline$<20$ & $63 \%$ & $50-74 \%$ \\
\hline \multicolumn{3}{|l|}{ Length-of-stay } \\
\hline$<1 \mathrm{~h}$ & $3 \%$ & $0-10 \%$ \\
\hline $1-6 h$ & $59 \%$ & $46-70 \%$ \\
\hline$>6 \mathrm{~h}$ & $38 \%$ & $27-51 \%$ \\
\hline \multicolumn{3}{|l|}{ Percent of ED visit leading to admission ${ }^{\mathrm{b}}$} \\
\hline$<20$ & $3 \%$ & $0-14 \%$ \\
\hline 20-39 & $84 \%$ & $68-94 \%$ \\
\hline $40-59$ & $13 \%$ & $5-29 \%$ \\
\hline 60 or higher & $0 \%$ & $0 \%$ \\
\hline \multicolumn{3}{|l|}{ Resources and capabilities } \\
\hline Physician in ED 24/7 & $99 \%$ & $92-100 \%$ \\
\hline Dedicated CT scanner & $39 \%$ & $28-52 \%$ \\
\hline Cardiac monitor & $99 \%$ & $92-100 \%$ \\
\hline Mechanical ventilator & $62 \%$ & $49-73 \%$ \\
\hline Respiratory isolation (negative-pressure room) & $51 \%$ & $38-63 \%$ \\
\hline Computer system to collect clinical data & $73 \%$ & $61-83 \%$ \\
\hline Internet access & $80 \%$ & $69-89 \%$ \\
\hline Clinical laboratory open round-the-clock & $83 \%$ & $72-91 \%$ \\
\hline
\end{tabular}

ED emergency department

${ }^{\mathrm{a} A m o n g}$ contiguous EDs only

${ }^{\mathrm{b}}$ Based on follow-up survey $(n=37)$

$\%$ reported the average length-of-stay as $>6 \mathrm{~h}$. Only $3 \%$ of EDs reported that their patients typically stayed $<1 \mathrm{~h}$. Most EDs reported that 20-39 \% of ED visits led to admission (Table 1).The ED appears to be a major route of hospital admission. Among the hospitals with inpatient beds available, $34 \%$ of EDs (95\% confidence interval (CI), 19-52 \%) reported that admissions from the ED constituted $>80 \%$ of all hospital admissions.

\section{Capacity}

While $25 \%$ of respondents ( $95 \%$ CI, 15-37 \%) considered their ED as operating at a good balance, $46 \%(95 \% \mathrm{CI}$, $34-59 \%$ ) considered it over capacity.

\section{Resources and capabilities}

The vast majority of EDs were staffed $24 / 7$ by physicians (99 \% CI, 92-100 \%). Technological support was high, with most EDs having cardiac monitors (99 \% CI, 92$100 \%$ ) and clinical laboratories (83 \% CI, 72-91\%) open $24 / 7$. However, internet and computer system access was variable (Table 1). Most emergency types could be treated 24/7 in sampled EDs (Table 3), with the notable exception of dental emergencies, which were treatable $24 / 7$ in only $3 \%$ of EDs (95\% CI, $0-11 \%$ ). The availability of consultants did not appear to correlate with the type of emergency that the EDs were capable of treating (Fig. 2). 
Table 2 Selected characteristics of EDs in Bogotá, Colombia, based on the original survey $(n=70)$ and follow-up survey $(n=37)$

\begin{tabular}{llll}
\hline & Original survey $(n=70)$ & Follow-up survey $(n=37)$ & $P$ value \\
\hline ED visits, median (IQR) & $61,637(30,000-107,317)$ & $44,457(19,920-129,215)$ & $0.47(33-186)$ \\
Hospital beds, median (IQR) & $100(16-204)$ & 3 \\
Percent of ED visits leading to admission & 29 & 84 \\
$<20$ & 37 & 13 \\
$20-39$ & 13 & 0 \\
$40-59$ & 10 & 0 \\
$60-79$ & 11 & \\
$80+$ & & 3 \\
Percent of total hospital admissions & 19 & 31 \\
admitted through the ED & 10 & 23 \\
$<20$ & 7 & 9 \\
$20-39$ & 15 & 34 \\
$40-59$ & 49 & \\
$60-79$ & & 3 \\
$80+$ & & 3 \\
\hline
\end{tabular}

\section{Discussion}

The NEDI-Bogotá survey was successfully implemented, with $>80 \%$ response rate among all EDs. In some ways, the Bogotá EDs are quite similar to those in the United States (US) [6, 13]. For example, the vast majority of EDs have a contiguous area with assessment of medical and surgical emergencies in the same area. In general, EDs are independent departments and most have essential technological resources, such as cardiac monitors and 24/7 clinical laboratories.
However, the survey also identified several important differences between typical EDs in Bogotá and the US. The population rate of ED visits in Bogotá ( 600 per 1000 people) is much larger than that seen in the US and several NEDI international surveys worldwide (Table 4). The reasons for this very high population rate are unclear, and it cannot be explained by high population density alone since this also would apply to other NEDI sites, such as Beijing [8]. Another factor that is frequently cited as a contributor to high ED visit volume is a relatively weak

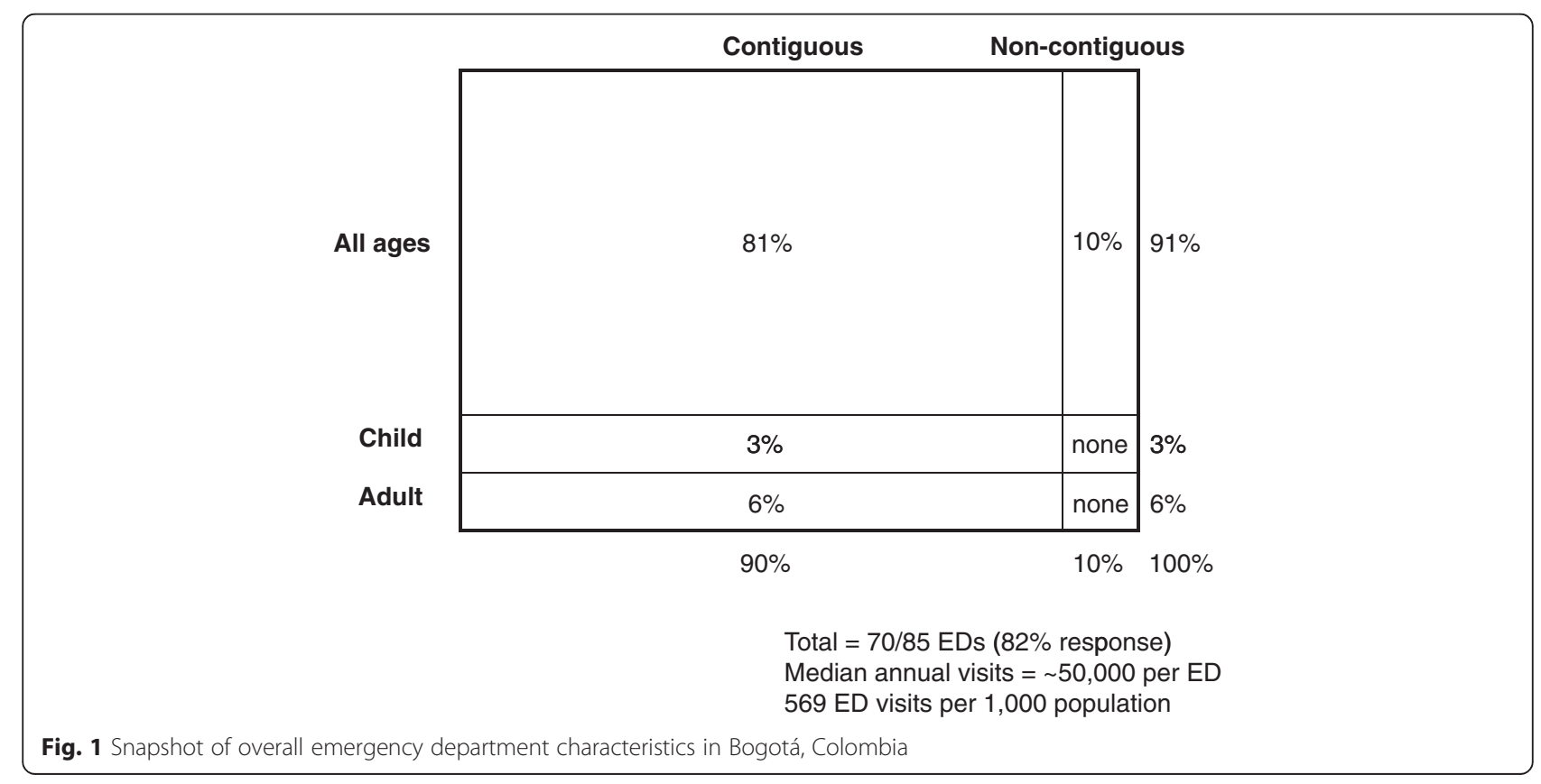


Table 3 Emergency types identified as treatable in surveyed emergency departments in Bogotá, Colombia ( $n=70,82 \%$ response rate)

\begin{tabular}{|c|c|c|c|}
\hline Emergency type & Example of emergency & Percentage of EDs able to treat 24/7 (\%) & $95 \%$ confidence interval (\%) \\
\hline Medical: cardiology & Arrhythmia, acute myocardial infarction & 73 & $61-83$ \\
\hline Medical: oncology & Fever and neutropenia & 22 & $13-34$ \\
\hline Medical: other & Urinary tract infection, acute asthma & 85 & $74-93$ \\
\hline Trauma & Motor vehicle crash, gunshot wound & 81 & $69-89$ \\
\hline $\begin{array}{l}\text { Neurological and } \\
\text { neurosurgical }\end{array}$ & $\begin{array}{l}\text { Acute thromboembolic stroke, intracranial } \\
\text { hemorrhage }\end{array}$ & 37 & $25-49$ \\
\hline Urological & Kidney stone & 55 & $43-67$ \\
\hline Obstetrical & Complications of pregnancy & 63 & $51-75$ \\
\hline Gynecological & Ruptured ovarian cyst, yeast infection & 57 & $44-69$ \\
\hline Ear, nose, throat & Severe epistaxis & 41 & $29-53$ \\
\hline Ophthalmological & Acute glaucoma, eye injury & 25 & $15-37$ \\
\hline Toxicological & Overdose, carbon monoxide poisoning & 61 & $38-63$ \\
\hline Psychiatric & Psychosis & 26 & $16-39$ \\
\hline Dental & Tooth extraction & 3 & $0-11$ \\
\hline Surgical: oral maxillofacial & Jaw fracture, oral abscess & 29 & $18-41$ \\
\hline Surgical: plastic & Severe lip laceration & 30 & $20-43$ \\
\hline Surgical: hand & Tendon injury & 30 & $20-43$ \\
\hline Surgical: orthopedic & Long bone fractures & 47 & $35-60$ \\
\hline Surgical: general & Acute appendicitis, pneumothorax & 60 & $48-72$ \\
\hline
\end{tabular}

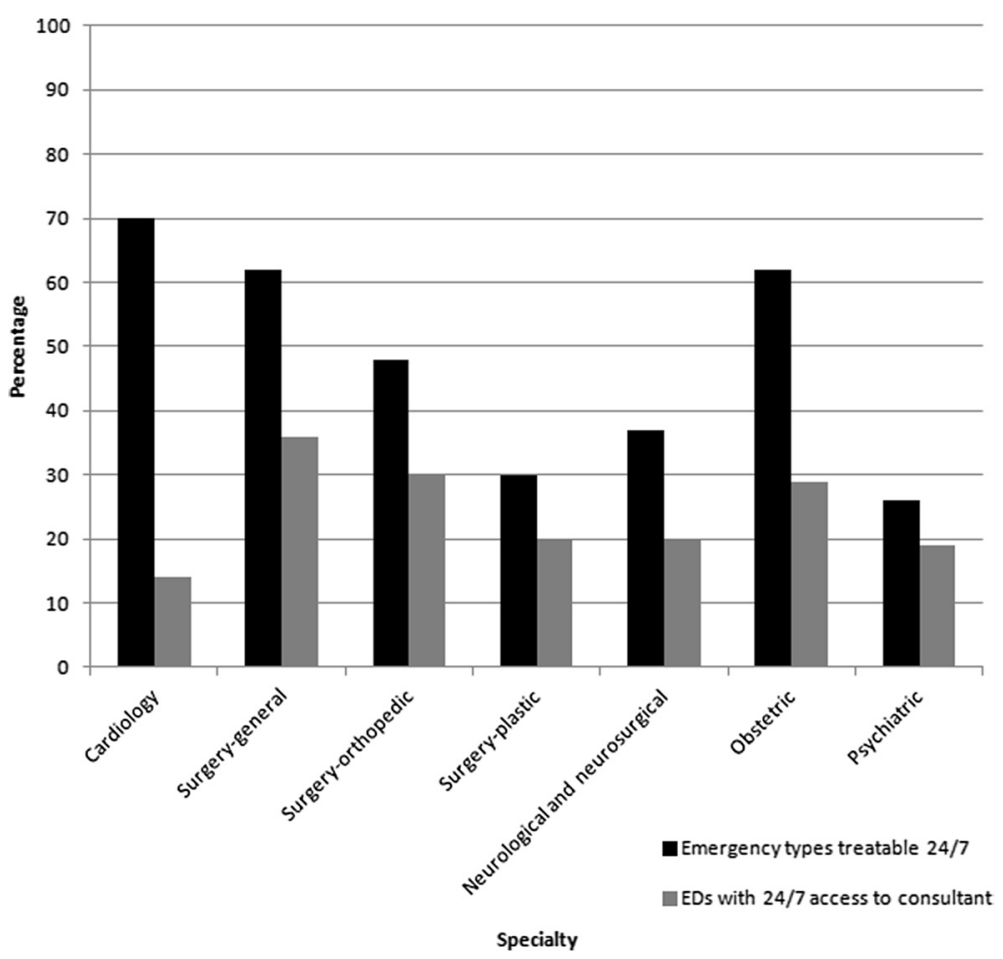

Fig. 2 Association between emergencies identified as treatable and availability of consultants in the emergency departments, by type of emergency 
Table 4 Summary of international National Emergency Department Inventories (NEDI), including the current study in Bogotá, Colombia

\begin{tabular}{llllll}
\hline Location (reference) & City vs country & Survey response & Contiguous ED for all ages (\%) & Median annual ED visits & ED visits per 1000 population \\
\hline Abuja, Nigeria [10] & City & $24 / 29=83 \%$ & 92 & 1500 & 54 \\
Beijing, China [8] & City & $36 / 41=88 \%$ & 36 & 80,000 & 167 \\
Singapore [12] & City/country & $14 / 14=100 \%$ & 86 & 39,450 & 197 \\
Slovenia [9] & Country & $55 / 68=81 \%$ & 90 & 6100 & 207 \\
Denmark [11] & Country & $28 / 34=82 \%$ & 39 & 32,000 & 196 \\
Switzerland [14] & Country & $122 / 138=88 \%$ & na & 8806 & 214 \\
USA [7] & Country & $>80 \%$ (multiple) & na & 20,351 & 437 \\
Bogotá, Colombia & City & $70 / 85=82 \%$ & 90 & $\sim 50,000$ & 569
\end{tabular}

ED emergency department, na not applicable

primary care system, but this situation would not necessarily apply to Colombia and does not provide a clear pattern when reviewing results from other cities/countries that have completed NEDI surveys [8-12, 14], particularly our report on Abuja, Nigeria [10].

Prior work on Colombian EDs is very limited. A survey of 560 patients with triage classifications that indicated a low acuity condition or one that could be treated in an outpatient clinic, from 28 Colombian EDs, examined reasons for visiting the ED instead of an outpatient clinic [15]. The most commonly reported reason $(23 \%)$ was that the person visited the ED because of a delay in his or her outpatient appointment; $15 \%$ said that making an outpatient appointment was too complicated, $15 \%$ of patients reported visiting an outpatient clinic without resolution of the problem, $13 \%$ stated a preference for the quality of emergency care, and $11 \%$ reported other reasons. Although it is tempting to generalize these results to the Bogotá EDs in the present study, further examination of these earlier data suggests caution. For example, although the six Bogotá EDs together contributed $45 \%$ of all ED visits in the 28-center dataset [15], these same six EDs correspond to only $7 \%$ of the 85 EDs that we identified in Bogotá $[15,16]$. While it is possible that they accurately represent at least some aspects of emergency care in Bogotá, it is likely that a focus on larger, more academically inclined EDs introduces a systematic error (bias) that complicates generalizations about the state of ED and emergency care in Bogotá, Colombia.

Other insights from our survey include the fact that most Bogotá EDs serve both children and adults, which is consistent with the practice observed in most prior NEDI international surveys, with the notable exception of Beijing, where $55 \%$ of EDs were dedicated to adults only [8]. Bogotá has a population one third the size of Beijing (20.6 million), but Bogotá has twice as many EDs, which suggests that Beijing probably has a larger percentage of institutions of increased complexity and quite different dynamics of health care. These crosscountry comparisons merit further investigation.
Furthermore, we found that most Bogotá EDs were able to care for many different types of emergencies, except for a notable lack of capability in the care of psychiatric, oncological, ophthalmological, and dental emergencies. These findings probably are explained by the fact that most Colombian doctors working in the ED are not specialized in emergency care or any other particular area; they are generalist physicians without particular training or expertise in the identified areas. Yet, the types of emergencies surveyed are all within the scope of practice of trained EM practitioners [17]. In settings limited by workforce constraints, there may be additional reason to train EM physicians with a core set of skills to address initial management of all common emergencies $[8,10]$.

Regarding the ED length-of-stay, 38 \% of EDs reported typical stays of over $6 \mathrm{~h}$ and $59 \%$ between 1 and $6 \mathrm{~h}$. In addition, about half of the EDs surveyed reported that they were over capacity. We believe this is largely due to the fact that most of the EDs are primarily primary care centers. In other words, many ED patients present with issues of low complexity, so ED stays are shorter in duration. This is in contrast with hospitals with more complex patients, where the ED length-of-stay can be more than $6 \mathrm{~h}$ due to ED boarding. Another aspect that may explain the long ED length-of-stay and over-capacity workload is the lack of specialists available to provide definitive interventions in patients. As a result, many patients must wait several hours to be seen by specialist consultants in internal medicine, surgery, and orthopedics. As part of the response to the lack of (and need for) specialists in emergency medicine (EM), Colombians began to recognize EM as a specialty in 1996, but today, more than 15 years later, Colombia has only five EM residency programs $[13,18,19]$. Together, these programs are able to deliver a maximum of $30 \mathrm{EM}$ specialists each year. Although this is an excellent start, the demand for emergency care greatly exceeds the capacity of the current residency training programs.

The NEDI-Bogotá survey demonstrates how EDs are the portal for most hospital admissions in Bogotá. 
Consequently, they play a fundamental role in overall hospital function and the economic status of most hospitals. Research is needed to address ED crowding and how to reduce it, including the potential role of fasttrack rooms and observation units. Although these are high-impact interventions of increasing popularity in the US EDs [20], the more frequent approach in Colombia is to simply expand the number of ED beds. Cross-country research provides opportunities for more rapid adoption of effective interventions in new settings.

\section{Limitations}

We recognize that this is an initial study with descriptive statistics, but it provides new information to guide efforts to advance emergency care in Bogotá. One limitation is that the NEDI survey is not validated. To our knowledge, a validated instrument to assess EDs worldwide does not exist. Questions from our survey were developed so that they could be used in diverse types of EDs [5]. Moreover, the survey questions have been used in several studies of US EDs $[6,20]$ and the actual NEDI-international instrument has been used successfully in several other countries $[8-12,14]$.

Another potential limitation is that this study relies on self-reported data. ED administrators were asked to supply data when available. When exact figures were unavailable, ED physicians-administrators provided their closest approximation. As the survey was anonymous, we do not suspect a systematic bias in the responses. We did note ED director uncertainty about the ED visit volume data on the original (main) survey, so we assessed the reliability of these data in a follow-up survey. By asking additional questions, we also had the opportunity to assess the internal consistency of the data and the responses were reassuring. We included the follow-up survey data for two items (annual ED visit volume, percent of ED visits that led to hospital admission), which were a little more conservative and more in line with the findings from several other NEDI-international surveys $([8-12,14]$; Table 3$)$.

Finally, the response rate in the study was $82 \%$, with 15 EDs choosing not to participate. If their experience or responses differed markedly from those studied, this could introduce bias. However, the missing sites did not differ in key parameters from the $>80 \%$ who did participate in our survey. We plan to perform repeat surveys of Bogotá EDs and anticipate that the growing familiarity with our approach and sincere interest in advancing Colombian emergency care will yield higher response rates in future years.

\section{Conclusions}

While EDs in the Colombian capital city, Bogotá, resemble US urban EDs in some ways, there are several major differences that raise questions of existing overcrowding and what will happen with the anticipated increase in ED utilization-and growing population. The NEDI-Bogotá survey provides basic descriptive information with a much larger sample than any prior study in Colombia. Like most research, it leads to further questions such as the precise reason for the high demand and long length-of-stay times. The survey also begins to describe the work environment for clinicians who provide emergency care. The generation of new data is essential to ongoing efforts to learn about emergency care models from diverse countries and, in so doing, help identify viable solutions to at least some of the problems shared by emergency physicians worldwide. At a more local level, it is important to remember that lessons from Bogotá may apply best to Bogotá. Several NEDI studies have shown how heterogeneous EDs are within single countries, and it is therefore critical to repeat similar surveys in other urban and rural regions of Colombia.

\section{Additional files}

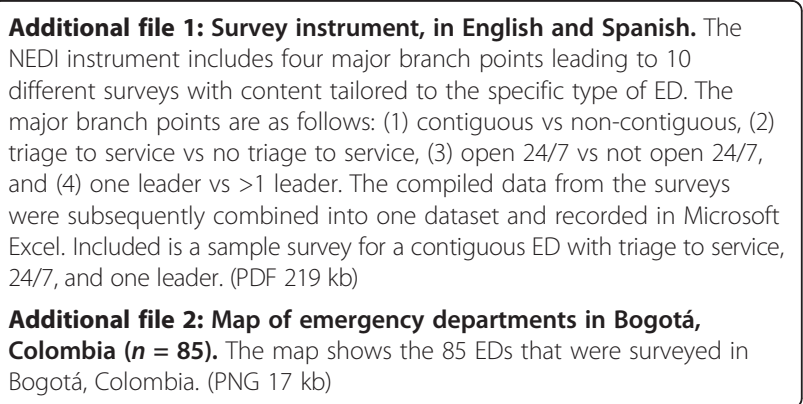

\section{Abbreviations}

Cl: confidence interval; ED: emergency department; EM: emergency medicine; EMNet: Emergency Medicine Network; NEDI: National ED Inventories; US: United States.

\section{Competing interests}

The authors declare that they have no competing interests.

\section{Authors' contributions}

YB participated in the data collection and helped draft the manuscript. JC participated in the data collection and provided critical revision of the manuscript. LSW participated in the analysis and interpretation of the data and preparation of the manuscript. AFS participated in the design of the study, in the analysis and interpretation of the data, and in the preparation of the manuscript. DKC helped coordinate the data collection, performed the data management, and provided the critical revision of the manuscript. Finally, CAC conceived of the study, participated in its design and coordination, and helped draft the manuscript. All authors read and approved the final manuscript.

\section{Acknowledgements}

We thank the survey participants for their important contributions to emergency care in Bogotá, Colombia. We also thank Drs. Juan Manuel Gutierrez, Jorge Otero, and Heriberto Puello for their support.

\section{Funding}

The funding of this study is through departmental funds. 


\section{Author details}

${ }^{1}$ Department of Emergency Medicine, Universidad del Rosario, Carrera $24 \mathrm{~N}^{\circ}$ 63C-69, Bogotá, Colombia. '2Department of Emergency Medicine, Universidad del Rosario/Hospital Universitario Mayor-Méderi, Bogotá, Colombia.

${ }^{3}$ Department of Emergency Medicine, Georgetown Washington University School of Medicine, Washington, DC, USA. ${ }^{4}$ Department of Emergency

Medicine, Massachusetts General Hospital, Boston, MA, USA

Received: 10 April 2015 Accepted: 28 July 2015

Published online: 08 August 2015

\section{References}

1. Departamento administrativo nacional de estadística DANE. Estimación y proyección nacional, departamental y municipal total por área 1985-2020. Available at: http://www.dane.gov.co/files/investigaciones/poblacion/ proyepobla06_20/7Proyecciones_poblacion.pdf. Accessed 23 Mar 2015.

2. Rodriguez $\mathrm{R}$, Infante $\mathrm{A}$. Universal health care for Colombians 10 years after Law 100: challenges and opportunities. Health Policy. 2004;68:129-42.

3. World Health Organization. Estadisticas sanitarias mundiales 2012. Available at: http://apps.who.int/iris/bitstream/10665/44858/1/9789243564449_spa.pdf. Accessed 23 Mar 2015.

4. Carreño JN. Marco legal del ejercicio médico en urgencias. In: Correa LF, editor. Guías par el manejo de urgencias. 3rathth ed. Bogotá, Colombia: Ministerio de la Protección Social; 2009. p. 587-91.

5. Steptoe AB, Corel B, Sullivan AF, Camargo Jr CA. Characterizing emergency departments to improve understanding of emergency care systems. Int J Emerg Med. 2011;4:42-50.

6. Sullivan AF, Richman IB, Ahn CJ, Bruce BS, Pallin DJ, Schafermeyer RW, et al. A profile of U.S. emergency departments in 2001. Ann Emerg Med. 2006;48:694-701.

7. Emergency Medicine Network (EMNet). The National ED Inventories survey instrument. Available at: www.emnet-nedi.org. Accessed 01 Mar 2013.

8. Wen LS, Xu J, Steptoe AP, Sullivan AF, Camargo Jr CA. A study of emergency department characteristics and capabilities in Beijing. China J Emerg Med. 2013;44:1174-9.

9. Jaklic B, Wen LS, Sullivan A, Camargo CA Jr. A profile of emergency departments in Slovenia. ISRN Emerg Med. 2012;461274. Available at: http://www.hindawi.com/isrn/em/2012/461274/cta/. Accessed 01 Mar 2014.

10. Wen LS, Oshiomogho Jl, Eluwa Gl, Steptoe AP, Sullivan AF, Camargo Jr CA. Characteristics and capabilities of emergency departments in Abuja. Nigeria Emerg Med J. 2012;29:798-801.

11. Wen LS, Anderson P, Stagelund S, Sullivan AF, Camargo Jr CA. National survey of emergency departments in Denmark. Eur J Emerg Med. 2012;20:205-9.

12. Wen LS, Venkataraman A, Sullivan AF, Camargo Jr CA. National inventory of emergency departments in Singapore. Int J Emerg Med. 2012;5:38.

13. Asociación Colombiana de Especialistas en Medicina de Urgencias y Emergencias. Academic Programs. Available at: http://www.acemcolombia.com/ home/en/academic-programs.html. Accessed 01 Mar 2014

14. Sanchez B, Hirzel AH, Bingisser R, Ciurea A, Exadaktylos A, Lehmann B, et al. State of emergency medicine in Switzerland: a national profile of emergency departments in 2006. Int J Emerg Med. 2013;6:23.

15. Agudelo J. Analisis comparativo de los servicios de urgencias 2008-2010. Hospitalaria. 2011;77:4-18. Available at: http://achc.org.co/hospitalaria/ revista.php?idart=956. Accessed 01 Mar 2014

16. Agudelo J. Primer proyecto de referenciación comparativo para indiciadores de calidad en servicios de urgencias en IPS afiliadas a la ACHC: avances y perspectivas. Hospitalaria. 2009;64:4-15. Available at: http://achc.org.co/ hospitalaria/revista.php?idart=771 Accessed 01 Mar 2014.

17. International EM. Core Curriculum and Education Committee for the International Federation for Emergency Medicine. International Federation of Emergency Medicine model curriculum for emergency medicine specialists. CJEM. 2011;3:109-21.

18. Lopez G, Vargas L. New specialty societies and academic programs enrich the training of dedicated emergency physicians in Colombia. Emerg Physicians Int. 2010;1:26-7.

19. Gomez L. Urgencias: una especialidad para el mundo moderno. latreia. 2005;18:344-51.

20. Handel DA, Ginde AA, Raja AS, Rogers J, Sullivan AF, Espinola JA, et al. Implementation of crowding solutions from the American College of Emergency Physicians Task Force Report on Boarding. Int J Emerg Med. 2010:3:279-86.

\section{Submit your manuscript to a SpringerOpen ${ }^{\odot}$ journal and benefit from:}

- Convenient online submission

- Rigorous peer review

- Immediate publication on acceptance

- Open access: articles freely available online

- High visibility within the field

- Retaining the copyright to your article

Submit your next manuscript at $>$ springeropen.com 